\title{
Optimizing the Role of Polymer Blend in the Preparation of Acyclovir Controlled- Release Tablets: An Approach for Better Patient Compliance
}

"Barkat Ali Khan ${ }^{1}$, Faheem Haider ${ }^{1}$, Kifayat Ullah Shah². Bushra Uzair ${ }^{3}$. Kaijian Hou, Muhammad Khurram Waqas ${ }^{5}$, Akhtar Rasul ${ }^{6}$

${ }^{1}$ Faculty of Pharmacy, Gomal University, Dera Ismail Khan 29500, Khyber

Pakhtunkhwa, Pakistan

${ }^{2}$ Department of Pharmacy, Quaid I Azam University, Islamabad, Pakistan

${ }^{3}$ Department of Bioinformatics and Biotechnology, International Islamic University, Islamabad, Pakistan

${ }^{4}$ Shantou Traditional Chinese Medical Hospital, Guangdong, China

${ }^{5}$ Institute of Pharmaceutical Science, UVAS, Lahore, Pakistan

${ }^{6}$ Department of Pharmacy, GC University, Faisalabad, Pakistan

Correspondence: barki.gold@gmail.com, Tel: +92-333-9732578

\begin{abstract}
:
This study was carried out to formulate and evaluate controlled release (CR) matrix tablets of Acyclovir using combination of hydrophilic and hydrophobic polymers. Acyclovir is a guanine derivative and is its half-life is short hence administered five times a day using immediate release tablets. Six formulations (F1-F6) were developed using Ethocel and Carbopol in equal combinations at drug-polymer (D:P) ratio of 10:5, 10:6, 10:7, 10:8, 10:9 and 10:10. Solubility study was performed using six different solvents. The compatibility studies were carried out using FTIR and DSC. According to USP, Quality Control and dimensional tests (hardness, friability, disintegration and thickness) were executed. In-vitro drug release studies of Acyclovir was carried out in dissolution apparatus using using $0.1 \mathrm{~N} \mathrm{HCl}$ medium at constant temperature of $37 \pm 0.5^{\circ} \mathrm{C}$. In order
\end{abstract}


to analyze the drug release kinetics, five different mathematical models were applied to the release data. The results showed that there was no incompatibility between drug and polymers. Physical QC tests were found within limits of USP. The release was retarded upto $24 \mathrm{hrs}$ and non-fickian in-vitro drug release mechanism was found. A formulation developed using blend of polymers, showed excellent retention and desired release profiles thus providing absolute control for $24 \mathrm{hrs}$.

Keywords: Acyclovir, Carbapol, Ethocel 


\section{Introduction}

The most frequently used route for administration of drugs is the oral route. The best and prevalent oral formulations available in the market are tablets and are favored by both patients and physicians equally. The most preferred formulations for chronic therapy are controlled release (CR) tablets for the reason that they offer better patient compliance [1]. The main objective of controlled release formulation is to offer appropriate carriage profiles in the range of therapeutic window [2-4].

The nature and characteristics of polymer play a significant role in release of Drug from reservoir, therefore their application can generate well branded dosage forms [1].

Among the most predominant means for oral controlled delivery of drug is the system of hydrophilic matrix and the principal of release of drug from hydrophilic matrices is based on swelling of the polymer when it interacts with the aqueous medium. The release of drug occurs then by means of diffusion, dissolution, and erosion [5-8].

The success of Acyclovir in treating Herpes simplex virus (HSV) has prompted the synthesis of several structural analogs, but none has shown to be as tolerable as and have shown to have such a high therapeutic index as acyclovir [9].

The most extensively used drug for genital herpes, cutaneous herpes, chicken pox, varicella zoster and herpes keratitis infections is Acyclovir. Generally acyclovir is used as $200 \mathrm{mg}$ tablets orally, five times a day [8]. Acyclovir is available in conventional immediate release tablet dosage form, Intravenous infusion (Zovirax ${ }^{\circledR}$ ) and 3\% ocular ointment, Liposomal, niosomal and magnet depot technology have also been investigated for the acyclovir by certain researchers $[10,11]$. Ethyl cellulose is an important polymer excessively used as drug retarding ingredient in the formulating sustained and controlled 
release pharmaceutical drug products. Ethyl cellulose alters the length and size of the diffusion path thereby controlling the release of the drug from the dosage form.

Carbomer is soft and white colored powder which can easily absorb water forming thick solutions and/ or gels. Carbomer is an inert, unchanging or stable substance. It has no any toxic effects and repel putrefaction and spoilage.

\section{Materials and Methods}

\subsection{Chemicals}

Acyclovir was provided as a gift sample from Glitz Pharmaceuticals, Islamabad, Pakistan. Potassium Phosphate Monobasic and Sodium Hydroxide were purchased from CBW Chemie GmbH Bitterfeld-Wolfen, Germany, Magnesium Stearate and Lactose was obtained from BDH Chemical Ltd, Pool England while Ethocel and Carbopol were taken from Dow Chemical Co. Midland USA. All the stated above chemicals were used without any further purification.

\subsection{Instruments}

The following instruments were used during this project. Dissolution Apparatus (Curio Pak, DL 0702), UV-Visible Spectrophotometer (1800 Shimadzu, Japan), Single Punch Tablet Machine (ZT, China), Hardness Tester (Curio Pak, HT 0321), Friability Apparatus (Curio Pak, FB 0498), Disintegrating Apparatus (Curio Pak, DT 0601).

\subsection{Construction of Standard Calibration Curve of Acyclovir}

For stock solution preparation $25 \mathrm{mg}$ of Acyclovir was taken in $50 \mathrm{ml}(0.5 \mathrm{mg} / \mathrm{ml})$ of manobasic phosphate buffer $(\mathrm{pH} 7.4)$ and was placed in ultra sonifier until the drug dissolution ensured completely. Suitable dilutions were prepared from the stock solution 
in descending order and then analyzed by means of UV-Spectrophotometer at $\lambda \max (254$ $\mathrm{nm})$. The corresponding absorbance values were noted and documented.

\subsection{Chemical Integrity}

FTIR spectra were measured for CR tablets of Acyclovir in order to investigate the effect on the functional group of Acyclovir. All samples were analyzed by a universal FTIR spectrum series at a resolution of $4 \mathrm{~cm}^{-1}$. For this purpose one sample of suitable quantity of pure drug and other containing pure drug along with polymers and excipients.

\subsection{Thermodynamic Behavior}

The thermal behavior of the prepared pure acyclovir powder and CR tablets of Acyclovir (Pure Acyclovir+polymers) was tested by Differential Scanning Calorimeter (DSC). Samples of specified quantity were placed in platinum crucible with heating range of $25-$ $500{ }^{\circ} \mathrm{C}$ having a heating rate of $10{ }^{\circ} \mathrm{C} \mathrm{min}^{-1}$.

\subsection{Solubility Study of Acyclovir}

According to the technique described by Higuchi and Connors solubility study was performed. Six different solvents i.e.Monobasic potassium phosphate buffer having $\mathrm{pH}$ 7.4, 7.2 and 6.8, purified water, $0.1 \mathrm{~N}$ Hydrochloric acid $(\mathrm{HCl})$ solution and $0.1 \mathrm{~N}$ Sodium hydroxide $(\mathrm{NaOH})$ solution were used for solubility.

\subsection{Acyclovir Tablet Formulation}

Acyclovir controlled release tablets (500 mg), comprising $200 \mathrm{mg}$ of Acyclovir and copolymers Ethocel and carbopol were formulated. The tablets were prepared at several drug-to-polymer ratios (D:P ratio of 10:5, 10:6, 10:7, 10:8, 10:9, and 10:10) using the slugging method and wet granulation method. Lactose was added as a diluent and magnesium Stearate $(0.5 \% \mathrm{w} / \mathrm{w})$ was used as a lubricant as given in table 1 . 
Table 1: Composition of $500 \mathrm{mg}$ controlled-release matrix tablets comprising Acyclovir: Ethocel: Carbopol (D:P Ratio 10:5, 10:6, 10:7, 10:8, 10:9, and 10:10)

\begin{tabular}{|c|c|c|c|c|c|c|c|}
\hline \multirow{2}{*}{$\begin{array}{l}\text { Formulatio } \\
\text { n code }\end{array}$} & \multirow{2}{*}{$\begin{array}{c}\text { Acyclovi } \\
\text { r } \\
\text { (active) }\end{array}$} & \multirow{2}{*}{$\begin{array}{c}\text { D:P } \\
\text { Rati } \\
\text { o }\end{array}$} & \multicolumn{2}{|c|}{ Polymers } & \multirow{2}{*}{$\begin{array}{c}\text { Filler } \\
\text { (lactose } \\
\text { ) }\end{array}$} & \multirow{2}{*}{$\begin{array}{l}\text { Lubricant } \\
\text { (Mg.Stearat } \\
\text { e) }\end{array}$} & \multirow{2}{*}{$\begin{array}{c}\text { Net } \\
\text { Weigh } \\
\text { t }\end{array}$} \\
\hline & & & $\begin{array}{c}\text { Carbopo } \\
l\end{array}$ & $\begin{array}{c}\text { Ethoce } \\
\text { l }\end{array}$ & & & \\
\hline F1 & $200 \mathrm{mg}$ & $10: 5$ & $50 \mathrm{mg}$ & $50 \mathrm{mg}$ & $\begin{array}{c}197.5 \\
\mathrm{mg}\end{array}$ & $2.5 \mathrm{mg}$ & $\begin{array}{l}500 \\
\mathrm{mg}\end{array}$ \\
\hline $\mathbf{F} 2$ & $200 \mathrm{mg}$ & $10: 6$ & $60 \mathrm{mg}$ & $60 \mathrm{mg}$ & $\begin{array}{c}177.5 \\
\mathrm{mg}\end{array}$ & $2.5 \mathrm{mg}$ & $\begin{array}{l}500 \\
\mathrm{mg}\end{array}$ \\
\hline F3 & $200 \mathrm{mg}$ & $10: 7$ & $70 \mathrm{mg}$ & $70 \mathrm{mg}$ & $\begin{array}{c}157.5 \\
\mathrm{mg}\end{array}$ & $2.5 \mathrm{mg}$ & $\begin{array}{l}500 \\
\mathrm{mg}\end{array}$ \\
\hline F4 & $200 \mathrm{mg}$ & $10: 8$ & $80 \mathrm{mg}$ & $80 \mathrm{mg}$ & $\begin{array}{c}137.5 \\
\mathrm{mg}\end{array}$ & $2.5 \mathrm{mg}$ & $\begin{array}{l}500 \\
\mathrm{mg}\end{array}$ \\
\hline F5 & $200 \mathrm{mg}$ & $10: 9$ & $90 \mathrm{mg}$ & $90 \mathrm{mg}$ & $\begin{array}{l}117.5 \\
\mathrm{mg}\end{array}$ & $2.5 \mathrm{mg}$ & $\begin{array}{l}500 \\
\mathrm{mg}\end{array}$ \\
\hline F6 & $200 \mathrm{mg}$ & $\begin{array}{c}10: 1 \\
0\end{array}$ & $100 \mathrm{mg}$ & $\begin{array}{l}100 \\
\mathrm{mg}\end{array}$ & $97.5 \mathrm{mg}$ & $2.5 \mathrm{mg}$ & $\begin{array}{l}500 \\
\mathrm{mg}\end{array}$ \\
\hline
\end{tabular}

2.8. Preparation of CR Tablets 
Formulations of all D:P ratios were mixed in a geometrical manner with the help of pestle and mortar for obtaining uniform mixture. The lubricant (Magnesium stearate) was not added in this mixture. 10\% Poly Vinyl Pyrolidone (PVP-K 30) solution was used as wetting agent. Subsequently the resultant humid mass was forcefully passed through sieve having mesh size number 8 for obtaining uniform size granules. The granules were kept for drying in tray dryer and sieving process was repeated with mesh size number 12. After drying, these granules were again passed through \#12 mesh screens to avoid formation of any lumps agglomerates. Later on when dried uniform size granules were obtained, lubricant was added to the dried granules of all formulations in specified amount. Final formulations of all ratios were eventually compressed into CR tablets of Acyclovir by single punch tablet machine.

\subsection{Determination of Tabletting Parameters}

After preparation of $\mathrm{CR}$ tablets of Acyclovir using wet granulation technique, they were subjected to various quality control tests for their physical characteristics investigation. Using standard operating procedure as described in USP their disintegration, thickness,, friability and hardness were determined. Digital vernier caliper was used for the thicknesses determination of all formulations. Friability, hardness and disintegration of all formulation were performed according to the standards of United State Pharmacopoeia (USP) protocol;s using hardness Apparatus, Friabililator and Disintegration Apparatus.

\subsection{In Vitro Drug Release}

Acyclovir CR tablets of all formulations were examined using USP Method-1 (Rotating Basket Method) for in vitro release studies. The media used, was $0.1 \mathrm{~N} \mathrm{HCl}$ which was 
kept at temperature of $37 \pm 0.5^{\circ} \mathrm{C} .5 \mathrm{ml}$ sample was taken with the help of syringe from each basket at definite intervals of time $(1,2,3,6,8,9,10,12,15,18,24$ hours). $5 \mathrm{ml}$ solvent was added to each basket so that net volume remains constant. All the samples were filtered by membrane filter having size of $0.45 \mu \mathrm{m}$ before taking their absorbance so that any extra particles or can be removed from samples. Absorbance of all sample were obtained with the help of UV-Visible Spectrophotometer at $254 \mathrm{~nm}$ and their percentage releases of each formulation were determined.

\subsection{In-vitro Release Kinetics}

In order to predict the physical mechanism of the Acyclovir in-vitro release behavior of all the formulations prepared with different D:P ratios $(10: 5,10: 6,10: 7,10: 8,10: 9$, and 10:10), release data were compared using the following mathematical models [12].

$$
\mathrm{W}=\mathrm{K}_{1} \mathrm{t}
$$

1. Kinetics of First order [13]

$$
\text { In }(100-W)=\operatorname{In} 100-K_{2} \mathrm{t}
$$

2. Kinetics of Higuchi [14]

$$
\mathrm{W}=\mathrm{K}_{4} \mathrm{t}^{1 / 2}
$$

3. Kinetics of Hixson Crowell [12]

$$
(100-\mathrm{W})^{1 / 3}=100^{1 / 3}-\mathrm{K}_{3} \mathrm{t}
$$

4. Equations of KorsmeyerPeppas [15]

$$
\mathrm{M}_{\mathrm{t}} / \mathrm{M} \infty=\mathrm{K}_{5} \mathrm{t}^{\mathrm{n}}
$$

Where

$\mathrm{W}=$ percent drug release at time $\mathrm{t}$.

$\mathrm{k}_{1}-\mathrm{k}_{4}=$ Constants ofrelease rates, depending on the kinetic model used. 
$\mathrm{M}_{\mathrm{t}} / \mathrm{M}_{\infty}=\quad$ The fraction of drug released.

$\mathrm{k}_{5}=$ Constant for integrating geometric and structural properties of tablets.

$\mathrm{n}=$ diffusion exponent for characterization of drug release transport mechanism

\section{Results and Discussion}

\subsection{Standard Calibration Curve of Acyclovir}

The standard calibration curve of Acyclovir was obtained using the method mentioned in previous section.

Using UV-Visible spectrophotometer, absorbance valves of stock solution of Acyclovir and its different dilutions were taken and plotted against its respective concentrations. Standard calibration curve of Acyclovir was constructed using Microsoft Excel and presented in Fig 1 along with equation of regression and $\left(\mathrm{R}^{2}\right)$ value. 


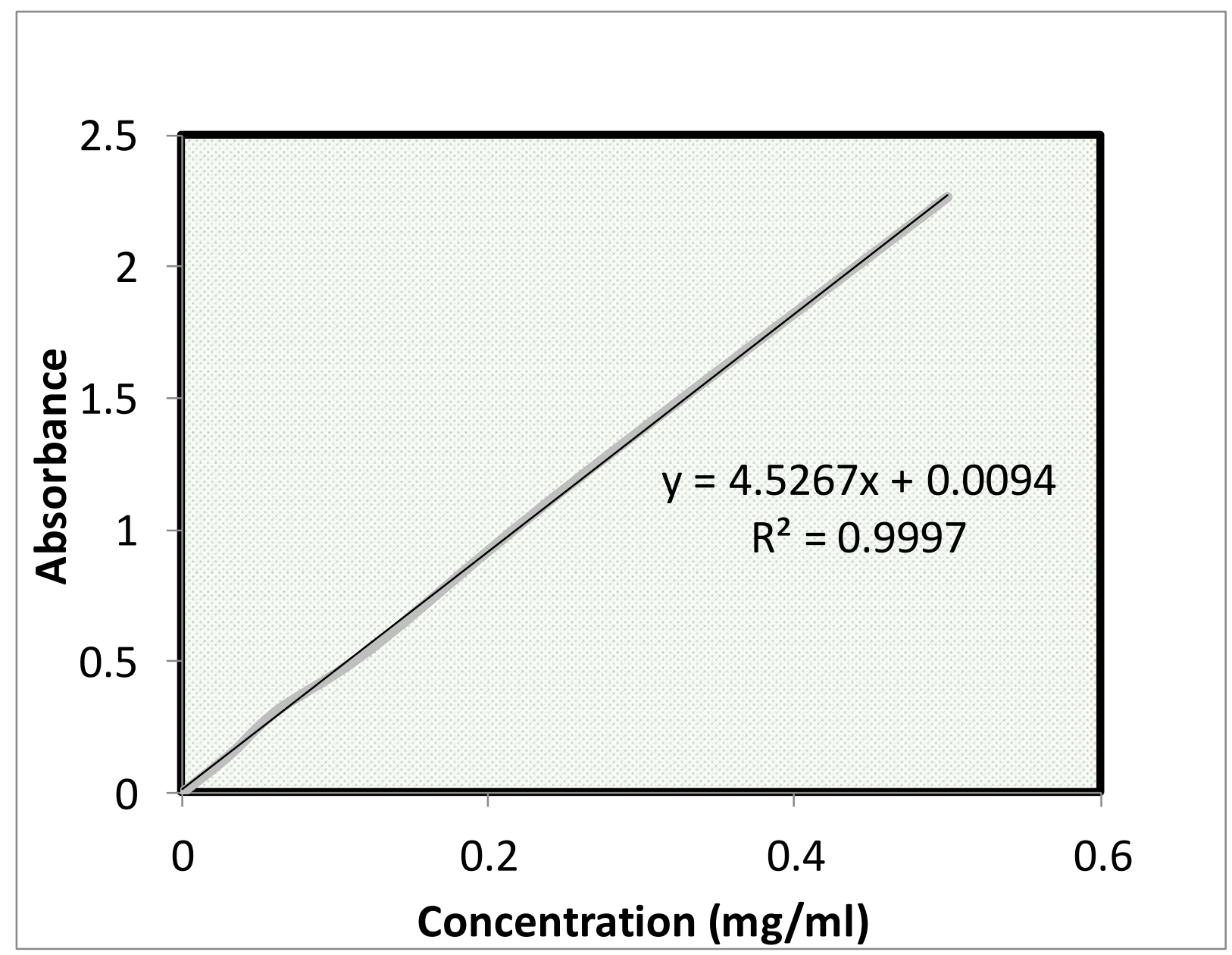

\section{2.}

Figure 1: $\quad$ Standard calibration curve of Acyclovir

For the assessment of any possible chemical interaction between pure drug and used polymer in the formulation, Fourier transform infrared spectroscopy (FTIR) spectra were taken for Acyclovir alone and with its mixture with Carbopol and Ethocel.

The FTIR spectra are illustrated in fig 2. First, the characteristic bands of the polymers and pure drug were observed as shown in fig, the main characteristic bands. The characteristic bands of pure Acyclovir acquired from the spectra of FT-IR were similar to those as documented in literature and shown in fig 2. The graph of pure Acyclovir overlaps on mixture of Acyclovir with polymers. The purity index was found to be 96.68 percent. 


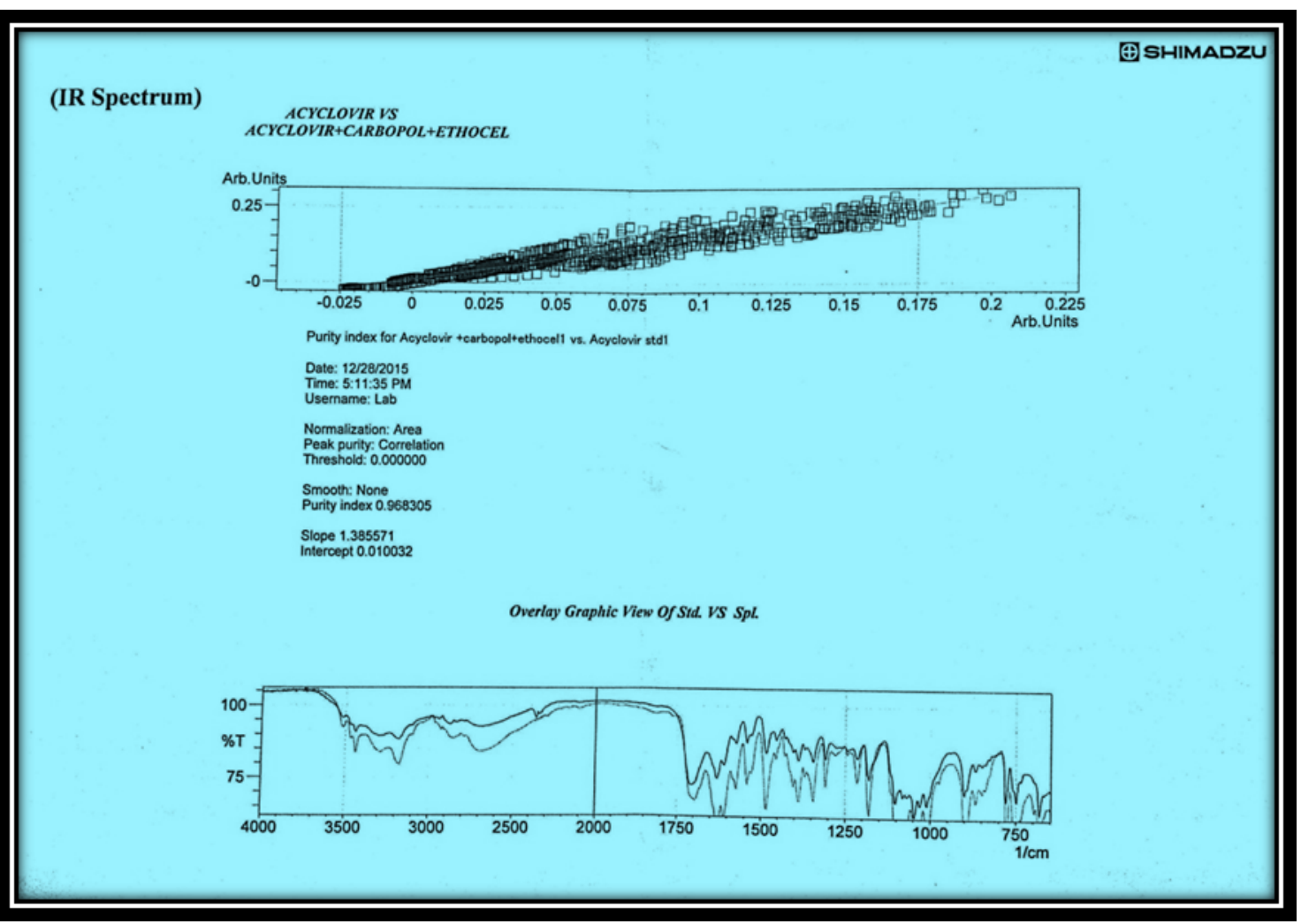

Figure 2: $\quad$ FTIR spectra ofAcyclovir pure drug its mixture with polymers

Ethocel-Carbopol represented good candidates for CR tablets of Acyclovir, where the obtained integrity was intact and Acyclovir release was sustained for $24 \mathrm{~h}$. Furthermore, the presented complex did not affect the chemical integrity or stability of the active drug.

\subsection{Thermodynamic Behavior of Acyclovir and its mixture with polymer}

DSC thermograms of untreated acyclovir, physical mixture of acyclovir with polymers in a ratio 10:5 and 10:10 (optimized acyclovir CR tablets) are shown in Figure 3 and 4 respectively. The thermal graphs of Acyclovir and its mixture ratio at 10:5 and 10:10 were almost similar signifying that they are compatible with each other. The physical mixture of acyclovir and polymers showed the same thermal behavior as the individual components, i.e. melting endotherm at 249 C. The endothermic peak, representing melting of acyclovir, vanished in the thermogram of acyclovir-encapsulated CR tablets. 
These findings are in accordance with previous findings reported by Musumeci et al and

Prerak et al $[16,17]$.

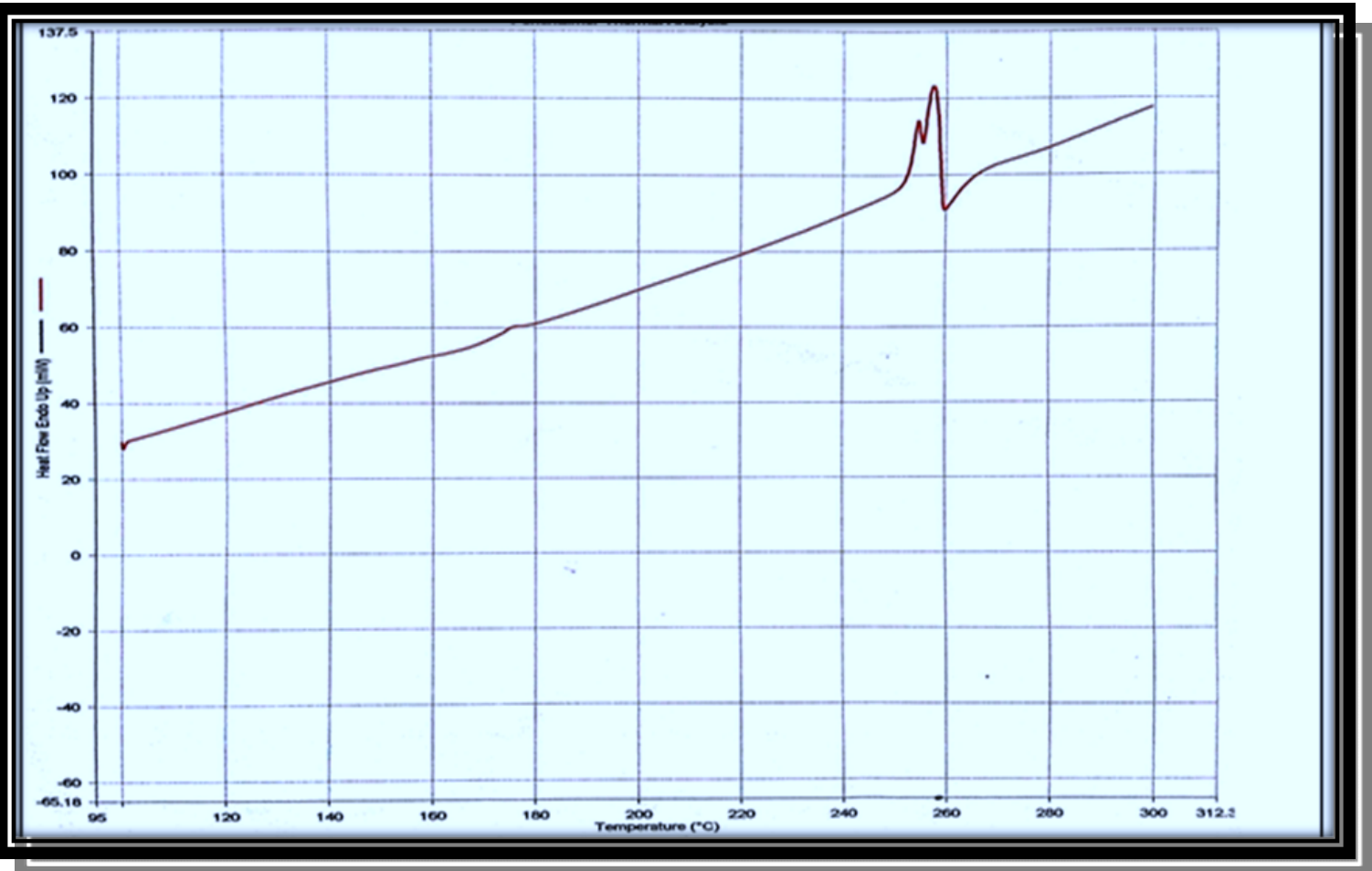

Figure 3: Acyclovir pure drug DSC thermogram 


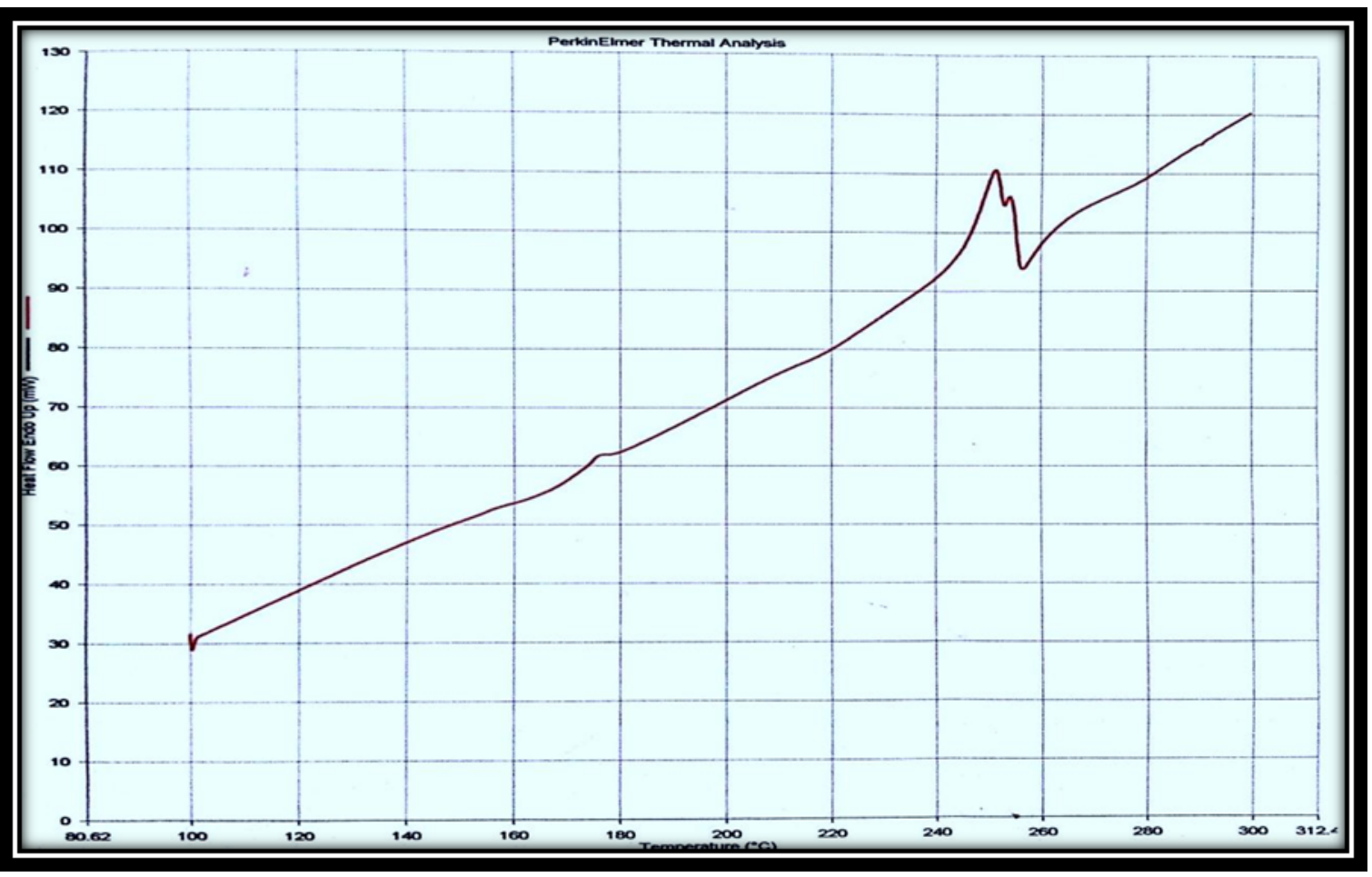

Figure 4: Acyclovir pure drug + Ethocel + Carbopol (10: 10) DSC thermogram

The physical mixture of acyclovir and polymers showed the same thermal behavior as the individual components, indicating that there was no interaction between the drug and the polymer in the solid state. The results suggested that the drug was molecularly dispersed in the polymers matrix and it might exhibit amorphous or disordered crystalline state as reported previously by Prerak et al [17].

\subsection{Solubility of Acyclovir}

The results obtained from solubility study are depicted by fig 6. Acyclovir has highest solubility in $0.1 \mathrm{~N} \mathrm{HCl}$ at $37{ }^{\circ} \mathrm{C}$. Among several phosphate buffers the solubility of Acyclovir was highest at $\mathrm{pH}$ 7.4. The least solubility has been observed in $0.1 \mathrm{~N} \mathrm{NaOH}$ at $25^{\circ} \mathrm{C}$ as shown in fig 6. 


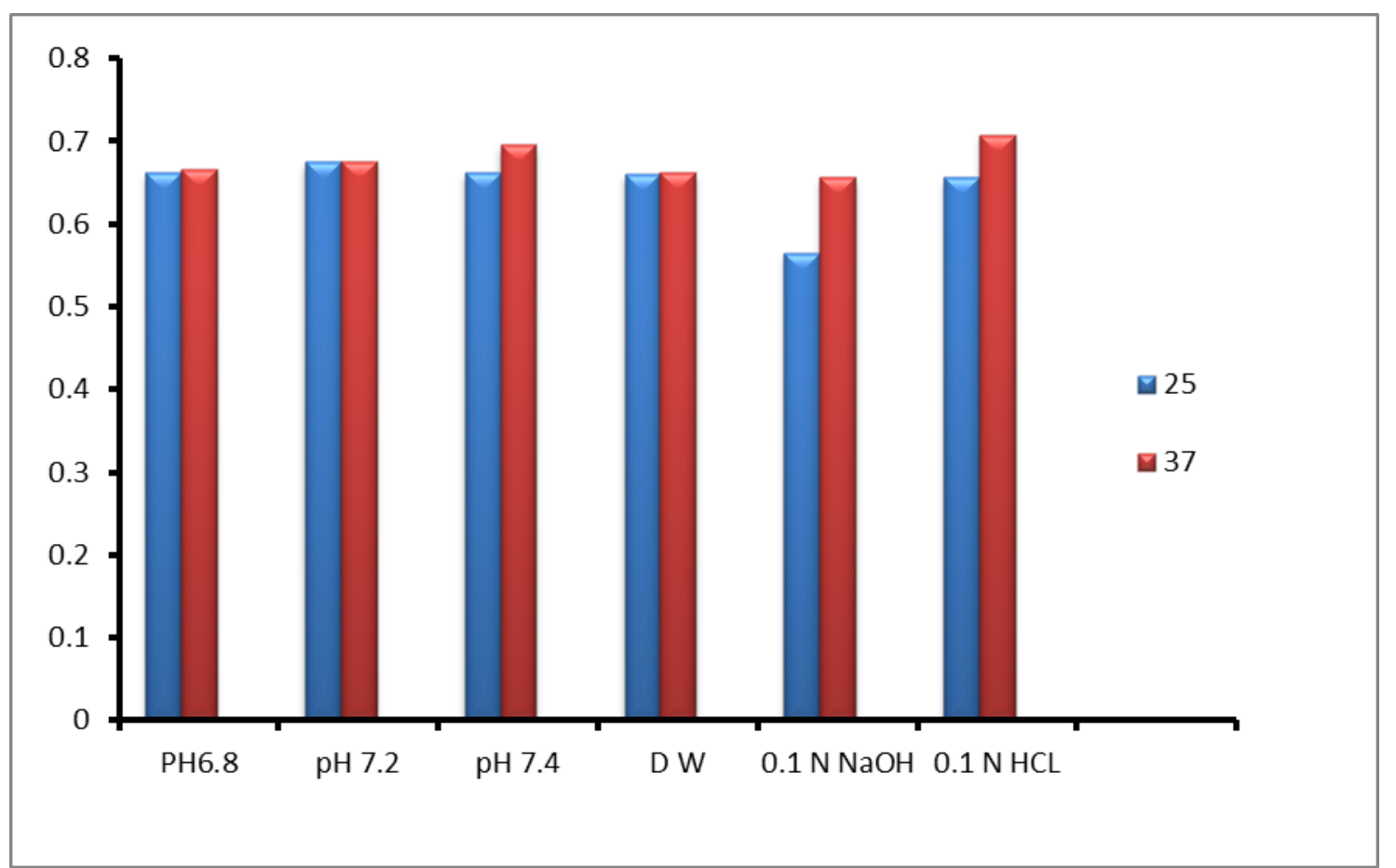

Figure 5: $\quad$ Solubility study results of Acyclovir in different solvents stored at 25 and $37^{\circ} \mathrm{C}$

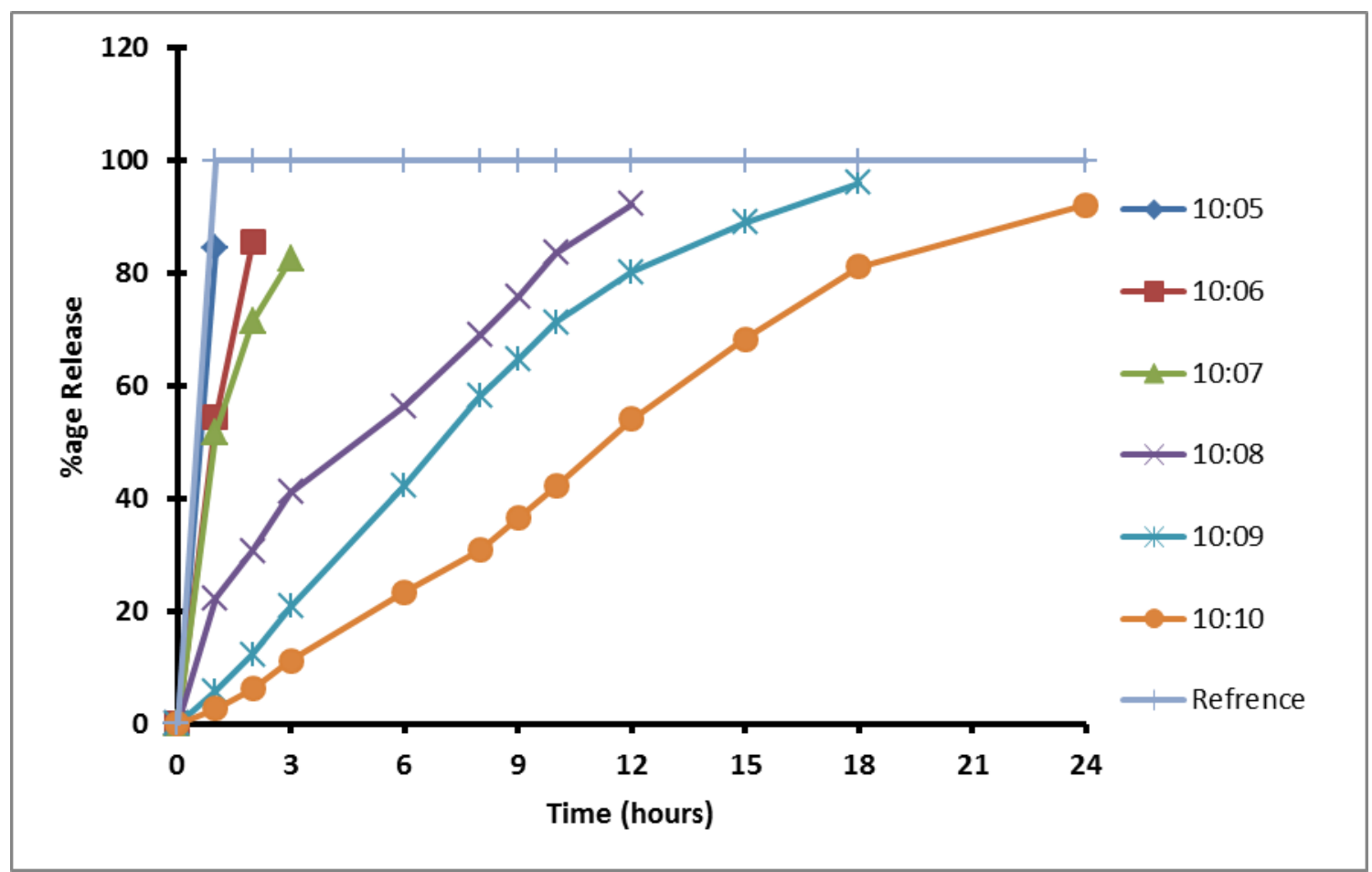

Figure 6: $\quad$ Release profile of Acyclovir with Carbopol and Ethocel at (D:P ratio 10:5, 10:6, 10:7, 10:8, 10:9, 10:10) and from Reference (immediate release formulation) 


\subsection{Tabletting Parameters Results}

Acyclovir control release tablets were prepared by wet granulation method, at different drug to polymer ratios of 10:5, 10:6, 10:7, 10:8, 10:9, and 10:10. The final formulations were inspected for their different physical characteristics. Tables 2 presented the thickness, hardness and friability, while table 3 shows the disintegration applied to CR tablets of Acyclovir with Carbopol and Ethocel. All the tablets of above mentioned formulations were well-made in look and were having smooth shiny surfaces. As displayed in table 2, the mean thickness of CR tablets of Acyclovir of all formulations, prepared by wet granulation technique with Carbopol and Ethocel were about $5 \mathrm{~mm}$ which are within the USP range (2-6mm).

Table 2: Results of Tabletting Parameters of Acyclovir CR tablets prepared by Wet granulation Method

\begin{tabular}{|c|c|c|c|}
\hline Formulation & Hardness $\left(\mathbf{k g} / \mathbf{c m}^{2}\right)$ & Thickness $(\mathbf{m m})$ & Friability (\%) \\
\hline F1 & $12 \pm 0.10$ & $5.5 \pm 0.15$ & $0.51 \pm 0.08 \%$ \\
\hline F2 & $13 \pm 0.12$ & $5.5 \pm 0.20$ & $0.54 \pm 0.1 \%$ \\
\hline F3 & $14 \pm 0.10$ & $5.49 \pm 0.17$ & $0.52 \pm 0.11 \%$ \\
\hline F4 & $14 \pm 0.15$ & $5.5 \pm 0.15$ & $0.53 \pm 0.08 \%$ \\
\hline F5 & $15 \pm 0.11$ & & $0.58 \pm 0.13 \%$ \\
\hline F6 & $16 \pm 0.13$ & $5.48 \pm 0.16$ & $0.63 \pm 0.15 \%$ \\
\hline
\end{tabular}

All values expressed in mean $\pm \mathrm{SD}$ 
Table 3: Results of Disintegration Test of Acyclovir CR tablets prepared by Wet granulation Method

\begin{tabular}{|c|c|c|c|}
\hline Formulation & D:P Ratio & Disintegration time of 6 & USP Range \\
Tade & & Buffer pH 6.8 & \\
\hline F1 & $10: 5$ & $12 \pm 0.09$ min. & NMT 45 min. \\
\hline F2 & $10: 6$ & $12 \pm 0.12 \mathrm{~min}$. & NMT 45 min. \\
\hline F3 & $10: 7$ & $13 \pm 0.15 \mathrm{~min}$. & NMT 45 min. \\
\hline F4 & $10: 8$ & $10 \pm 0.11 \mathrm{~min}$. & NMT 45 min. \\
\hline F5 & $10: 9$ & $12 \pm 0.15 \mathrm{~min}$. & NMT 45 min. \\
\hline F6 & $10: 10$ & $13 \pm 0.15 \mathrm{~min}$. & NMT 45 min. \\
\hline
\end{tabular}

All values expressed in mean \pm SD

The mean hardness of CR tablets of Acyclovir of all formulations with Carbopol and Ethocel, waw in the range from 12-16 which were within the USP satisfactory limits i.e. $\left(10-20 \mathrm{~kg} / \mathrm{cm}^{2}\right)$, the hardness of formulation 10:10 D: P ratio was maximum as compared to rest of formulations due to use of high fraction of polymers.

Disintegration tests were then applied to all formulations as given in table 3 . Tablets with Carbopol and Ethocel were disintegrated within 15 minutes. The friability tests were performed after disintegration tests for all formulations of Acyclovir with Carbopol and Ethocel. The results of all formulations were within USP satisfactory friability range, the mean value of friability was less than $0.8 \%$. 


\subsection{Drug Release Studies}

As displayed in figure $4 \mathrm{CR}$ Acyclovir tablets formulations prepared by wet granulation method at different drug to polymer ratio of 10:5, 10:6, 10:7, 10:8, 10:9, and 10:10. The formulations of D: P ratio 10: 10 prolong the release of Acyclovir drug to a more extent and the $96 \%$ of whole the drug was released in 24 hours. The release from 10: 5 was extended only up to 1 hour and $84.39 \%$ drug was released. The second formulation 10:6 extended the release up to 2 hours. The third formulation 10: 7 prolonged the release time to 6 hours. The release of drug was extended up to 12 hours by fourth formulation. From formulation of 10: 9 the release was much slower and extended to 18 hours. Final formulation 10:10 gave us the desired result and release of drug was extended up to 24 hours.

The results of in vitro dissolution study of each formulation (D:P ratio 10:10) are taken with the help of USP method 1 according to the procedure mentioned in methodology section. The results of each formulation have been shown individually in figure 6 . The rate of the drug release (until 24 hours) tended to decrease with increase amounts of either Carbapol or ethocel. According to literature findings, the slowing effect of both polymers is due to increases in the viscosity of the gel layer around the matrix tablet $[18,19]$. Both polymers have a affinity of making gel when they come into contact with aqueous layer. So, at high levels, polymer concentrations are increased around the tablet, and so is the viscosity of the outer layer, which results in decreases in the release of the drug, which then subsequently limits the release of the drug from the matrix [18]. Gel creation occurs due to dissociation of the carboxyl groups of Carbapol at a $\mathrm{pH}$ above their $\mathrm{pK}_{\mathrm{a}}$ (i.e., $6.0 \pm 0.3$ ), which causes uncoiling and the development of molecules due to the 
production of an electrostatic repulsive force between the negatively charged carboxyl groups. Uncoiling and expansion of the molecules result in polymer swelling and, consequently, gel is formed, which consists of closely packed swollen particles. With increases in the amount of polymer, this gelling property increases, and thicker gel restrains water penetration, which ultimately reduces the release of the drug. At high levels of both polymers, a considerable fraction of the drug $(\sim 16 \%)$ remained unreleased until 24 hours, which may result in reductions in the extent of bioavailability significantly. Charyulu et al prepared acyclovir controlled release tablets using HPMC $\mathrm{K} 15 \mathrm{M}$ and sustained the release for $10 \mathrm{hrs}$. Similarly CHAUDHARI et al formulated controlled release tablets of acyclovir using hydrophilic polymer, polyethylene oxide and the maximum sustained action was observed for $12 \mathrm{hrs}[20,21]$. Acylex ${ }^{\circledR}$ by Ferozsons (pvt) Ltd Noshehra, Pakistan was used as a reference drug which gave $100 \%$ release after 40 Minutes.

\section{7. $\quad$ Kinetic Analysis of Drug Release Data}

Kinetic analysis of drug release data was done by using the mathematical models [19]. It was found that the formulation F6 followed zero order release and formulations F1, F2, F3, F4 and F5 followed first order release as shown in table 4. The data of the various models revealed that formulations F1, F2, F3, F4 and F5 followed Higuchi matrix model whereas formulations F6, follows Korsmeyer-Peppas model. In case of formulation F6 the $\mathrm{n}$ value for Korsmeyer-Peppas model was found to be in range less than 0.5 , which indicates mechanism of drug release by Fickian diffusion whereas in case of formulations F1, F2, F4 and F5 the n value for Korsmeyer 
Peppas model was found to be more than 0.5 , which indicates mechanism of drug release by non fickian diffusion by those formulations.

Table 4: Kinetic models Parameters applied to release profile of CR tablets

\begin{tabular}{|c|c|c|c|c|c|c|c|c|c|c|c|c|}
\hline S.No & $\begin{array}{l}\text { Kinetic } \\
\text { model }\end{array}$ & $\mathbf{k}_{1}$ & $\mathbf{r}_{1}$ & $\mathbf{k}_{2}$ & $\mathbf{r}_{2}$ & $\mathbf{k}_{3}$ & r3 & $\mathbf{k}_{4}$ & $\mathbf{r}_{4}$ & $\mathbf{k}_{5}$ & $\mathbf{r}_{5}$ & $\mathbf{N}$ \\
\hline 1 & $\mathbf{W}=\mathbf{k}_{1} \mathbf{t}$ & 1.02 & 0.21 & & & & & & & & & \\
\hline 2 & \multicolumn{3}{|c|}{$(100-w)=\ln 100-k_{2} t$} & 0.05 & 0.889 & & & & & & & \\
\hline 3 & \multicolumn{5}{|c|}{$(100-w)^{1 / 3}=100^{1 / 3}-k_{3} t$} & 0.16 & 0.897 & & & & & \\
\hline 4 & \multicolumn{7}{|l|}{$W=k_{4} t^{1 / 2}$} & 2.03 & 0.975 & & & \\
\hline 5 & \multicolumn{9}{|c|}{$\mathbf{M}_{\mathbf{t}} / \mathbf{M}_{\infty}=\mathbf{k} 5 \mathbf{t}^{\mathrm{n}}$} & 3.13 & 0.994 & 0.965 \\
\hline
\end{tabular}

\section{Conclusion}

Based on the results of these studies, it was concluded that the blend of Ethocel and Cabapol polymers can be used as efficient matrix former to provide controlled release of acyclovir. The formulation F6 can retard the drug release rate up to 24 hours which can lead to OD dose and can enhance patient compliance as the usual dose is QID. In the present work, $1^{\text {st }}$ time the attempt has been made, formulating CR tablets of acyclovir using blend of hydrophillic and hydrophobic polymers. It is suggested to perform pharmacokinetic parameters ( $\left.\mathrm{t}_{1 / 2}, \mathrm{Cmax}, \mathrm{Tmax}\right)$ and IVIVC in-vivo.

\section{Acknowledgement}


The authors are thankful to Leads Pharmaceutical Industries (pvt) Ltd Islamabad for providing the pure sample of acyclovir and necessary research facilities to carry out this work.

\section{Author contributions}

Faheem Haider carried the research work. Dr Barkat Ali Khan supervised the project. All other co-authors contributed in the provision of resources, data analysis, final editing.

\section{Disclosure}

The author reports no conflicts of interest in this work.

\section{References}

1. Harsha Sonaye, Shagufta Khan, Pritish Kurumkara. Formulation And Evaluation Of Controlled Release Matrix Tablet Of An Antiviral Drug. International Journal of PharmTech Research. 5(3):1165-1178;2013.

2. Chen X, Wen H and Park K. Challenges and new technologies of oral controlled release. Oral controlled release formulation design and drug delivery: Theory to Practice, 16; 257-277; 2010

3. Grundy JS and Foster RT. The nifedipine gastrointestinal system: Evaluation of pharmaceutical, pharmacokinetic and pharmacological properties. Clinical Pharmacokinetics, 30: 28-51; 1996.

4. Lordi NG. Sustained release dosage form: In theory and practice of industrial pharmacy. 3rd ed. Philadelphia, USA: Lea and Febiger. 430-456;1986.

5. Levina $\mathrm{M}$ and Rajabi-Siahboomi AR. The influence of excipients on drug release from Hydroxypropylmethylcellulose matrices. J. Pharm. Sci, 97: 2746-2754; 2004.

6. Colombo P.Swelling-controlled release in hydrogel matrices for oral route. Adv, Drug. Deliv. Rewiews, 11: 37-57; 1993. 
7. Siepmann J and Peppas NA.. Modeling of drug release from delivery systems based on hydroxypropyl methylcellulose (HPMC). Adv Drug Deliv Rev, 48: 139157; $2001 \mathrm{a}$

8. Sumeet Dhaliwal, Subheet Jain, Hardevinder P. Singh, and A. K. Tiwary.Mucoadhesive Microspheres for Gastroretentive Delivery of Acyclovir: In Vitro and In Vivo Evaluation.American Association of Pharmaceutical Scientists. $10(2): 322-330 ; 2008$.

9. Patrizia Chetoni, Daniela Monti, Silvia Tampucci, Barbara Matteoli, Luca Ceccherini-Nelli, Alessando Subissi, Susi Burgalassi. Liposomes as a potential ocular delivery system of distamycin A. International Journal of Pharmaceutics. Aug 2015, Vol. 492: 120-126

10. Rüdiger Gröninga, Michael Berntgena, Manolis Georgarakis. Acyclovir serum concentrations following peroral administration of magnetic depot tablets and the influence of extracorporal magnets to control gastrointestinal transit. Biopharmaceutics. 46, Issue 3, 1 November 1998, Pages 285-291

11. Stacy D. Brown, Michael G. Bartlett, and Catherine A. White. Pharmacokinetics of Intravenous Acyclovir, Zidovudine, and Acyclovir-Zidovudine in Pregnant Rats. ANTIMICROBIAL AGENTS AND CHEMOTHERAPY. 47 (3): 991996;2003.

12. Tiwari SB and Rajabi-Siahboomi AR. Modulation of drug release from hydrophilic matrices. Pharmaceutical Technology, Europe. 1: 1-8;2008.

13. FORD, J.L.; RUBINSTEIN, M.H.; HOGAN, J.E. Formulation of sustained release promethazine hydrochloride tablets using hydroxypropyl methyl cellulose matrices. Int. J. Pharm. 24;327-338, 1985.

14. VAZQUES, M.J.; PEREZ, M.B.; GOMEZ, J.L.; MARTINEZ, P.R.; SOUTO, C.; CONCHEIRO, A. Influence of technological variables on release of drugs from hydrophilic matrices. Drug Dev. Ind. Pharm.18, p.1355-1375, 1992. 
15. SKOUG, J.W.; MIKELSONS, M.V.; VIGNERON, C.N.; STEMM, N.L. Qualitative evaluation of the mechanism of release of matrix sustained release dosage forms by measurement of polymer release. J. Control. Release,27, 227$245,1993$.

16. Musumeci T, Ventura CA, Giannone I. PLA/PLGA nanoparticles for sustained release of docetaxel. Int J Pharm 2006; 325:172-179.

17. Prerak J. Patel, Mukesh C. Gohel, and Sanjeev R. Acharya. Exploration of statistical experimental design to improve entrapment efficiency of acyclovir in poly (d, l) lactide nanoparticles. Pharm Dev Technol 2013. DOI: $10.3109 / 10837450.2013 .769566$.

18. Charyulu Narayana, Patel Kishan, Jose Jobin. FORMULATION AND EVALUATION OF ACYCLOVIR MATRIX TABLET USING MUCOADHESIVE POLYMER. Journal of Drug Delivery \& Therapeutics; 2013, $3(5), 52-57$

19. CHAUDHARI SHILPA P, KAMBLE SHRENIK C., SALVANKAR SHAILENDRA S. DESIGN \& IN-VITRO EVALUATION OF GASTRORETENTIVE, SUSTAINED RELEASE TABLET FORMULATION OF ACYCLOVIR USING HYDROPHILIC POLYMERS. Int J Pharm Pharm Sci, Vol 5, Suppl 4, 111-116

20. SINGH, B.; DAHIYA, M.; SAHARAN, V.; AHUJA, N. Optimizing drug delivery systems using systematic "design of experiments". Part II: Retrospect and prospects. Crit. Rev. Ther Drug Carrier. Syst. 22, p.215-294, 2005

21. SURYAKANTA, S.; DINDA, S.C.; SARWAR, B.; SRUTI, J.; VIKAS, S.; BHANOJI, R. Design and characterization of oral sustained release mucoadhesive matrix tablets of didanosine. Asian J. Pharm. Sci. Res.1, 38-60, 2011. 